\title{
Fluorescent Phosphatidylinositol 4,5-Bisphosphate Derivatives with Modified 6-Hydroxy Group as Novel Substrates for Phospholipase C
}

\author{
Xiaoyang Wang ${ }^{\dagger}$, Matthew Barrett ${ }^{\ddagger}$, John Sondek ${ }^{\ddagger}$, T. Kendall Harden ${ }^{\ddagger}$, and Qisheng \\ Zhang ${ }^{\dagger,}{ }^{*}$ \\ tDivision of Chemical Biology and Medicinal Chemistry, University of North Carolina at Chapel \\ Hill, Chapel Hill, North Carolina 27599, United States \\ ‡Department of Pharmacology, University of North Carolina at Chapel Hill, Chapel Hill, North \\ Carolina 27599, United States
}

\section{Abstract}

The capacity to monitor spatiotemporal activity of phospholipase C (PLC) isozymes with a PLCselective sensor would dramatically enhance understanding of the physiological function and disease relevance of these signaling proteins. Previous structural and biochemical studies defined critical roles for several of the functional groups of the endogenous substrate of PLC isozymes, phosphatidylinositol 4,5-bisphosphate $\left(\mathrm{PIP}_{2}\right)$, indicating that these sites cannot be readily modified without compromising interactions with the lipase active site. However, the role of the 6-hydroxy group of $\mathrm{PIP}_{2}$ for interaction and hydrolysis by PLC has not been explored, possibly due to challenges in synthesizing 6-hydroxy derivatives. Here, we describe an efficient route for the synthesis of novel, fluorescent PIP $_{2}$ derivatives modified at the 6-hydroxy group. Two of these derivatives were used in assays of PLC activity in which the fluorescent PIP $_{2}$ substrates were separated from their diacylglycerol products and reaction rates quantified by fluorescence. Both $\mathrm{PIP}_{2}$ analogues effectively function as substrates of PLC- $\delta 1$, and the $K_{\mathrm{M}}$ and $V_{\max }$ values obtained with one of these are similar to those observed with native $\mathrm{PIP}_{2}$ substrate. These results indicate that the 6-hydroxy group can be modified to develop functional substrates for PLC isozymes, thereby serving as the foundation for further development of PLC-selective sensors.

\footnotetext{
(C) 2012 American Chemical Society

*Corresponding Authorqszhang@unc.edu; Tel 919-966-9687. ASSOCIATED CONTENT

Supporting Information

Experimental procedures and NMR spectra of key compounds. This material is available free of charge via the Internet at http:// pubs.acs.org.

Notes

The authors declare no competing financial interest.
} 


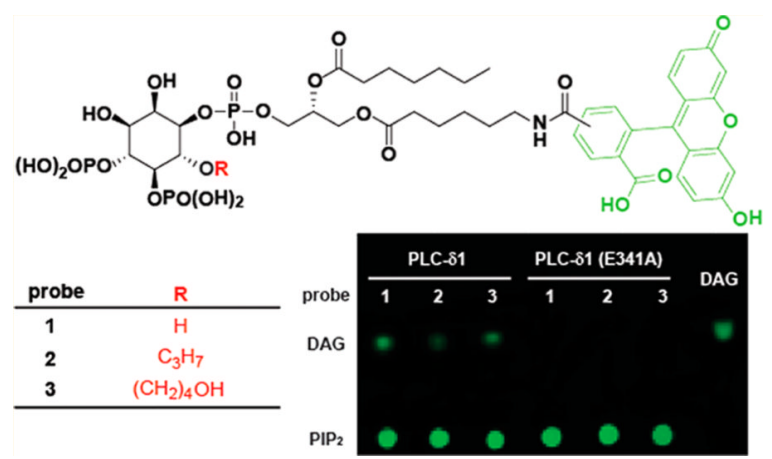

The phospholipase C (PLC) family of enzymes catalyze the hydrolysis of membrane-bound phosphatidylinositol 4,5-bisphosphate $\left(\mathrm{PIP}_{2}\right)$ to form the second messengers, diacylglycerol (DAG) and inositol 1,4,5-trisphosphate $\left(\mathrm{IP}_{3}\right) .{ }^{1}$ Diacylglycerol activates protein kinase $\mathrm{C}$ (PKC) while $\mathrm{IP}_{3}$ activates calcium channels leading to the release of $\mathrm{Ca}^{2+}$ from endothelial reticulum to cytosol. ${ }^{2}$ In addition, PLC action also regulates local $\mathrm{PIP}_{2}$ pools leading to changes in subcellular localization and/or function of a broad range of $\mathrm{PIP}_{2}$-interacting proteins, including numerous ion channels. Consequently, PLCs are essential signaling proteins that regulate diverse cellular processes, including proliferation ${ }^{3}$ and differentiation, ${ }^{4}$ vasculogenesis, ${ }^{5}$ and fertilization. ${ }^{6}$ Aberrant regulation of PLCs has been implicated in diseases including cancer, ${ }^{7-13}$ heart diseases,,${ }^{14}$ and neuropathic pain. ${ }^{15}$

The 13 mammalian PLC isozymes are broadly grouped into six families $(-\beta,-\gamma,-\delta,-\varepsilon$, $-\zeta,-\eta)$ based on their sequence homologies and functions. Various extracellular stimuli activate different PLC isoforms through distinct mechanisms. For example, agonists of Gprotein coupled receptors (GPCRs) activate PLC- $\beta$ isozymes through Gaq- and G $\beta \gamma$ subunits of heterotrimeric G proteins, while PLC- $\gamma$ activity is enhanced through phosphorylation promoted by receptor and non-receptor tyrosine kinases. In addition, PLC- $\varepsilon$ and certain members of the PLC- $\beta$ and PLC- $\gamma$ subclasses of isozymes are activated by Ras, ${ }^{1}$ Rho, ${ }^{17}$ and Rac subfamilies of small GTPases. ${ }^{18}$ However, when, where, and how various PLC isoforms are activated under different extracellular stimuli are still not well understood. This is partly due to the lack of methods to monitor the spatiotemporal activities of cellular PLCs.

Standard, radioisotope-based assays are discontinuous and cannot be used to monitor the real-time dynamics of PLC activity in cells. Cell permeable dyes that increase in fluorescence upon binding calcium are also routinely used as complementary methods to monitor PLC activity. However, although such assays are simple and throughput is high, they are not a direct measure of PLC activity and often generate confounding data since other factors also contribute to intracellular calcium concentration.

With the long-term goal of spatiotemporal monitoring of inositol lipid signaling, we initiated studies to develop small molecule sensors of PLCs. Previous kinetic studies demonstrated that the 2-hydroxy (2-OH) in $\mathrm{PIP}_{2}$ is essential ${ }^{19-21}$ for its hydrolysis by PLCs and that 3phosphoinositides are not PLC substrates. ${ }^{22}$ Similarly, removal of the phosphate group from the 4- or 5-OH positions resulted in derivatives that are poor substrates for PLCs.

Furthermore, the stereochemistry of the ${ }_{\mathrm{D}}$-myo-insoitol headgroup, but not the diacylglycerol side chain, was shown to be critical for effective PLC-mediated catalysis. ${ }^{23}$ Finally, alkyl substitutions at the $s n-1$ and $s n-2$ positions resulted in PIP $_{2}$ molecules that still function as PLC substrates. ${ }^{24}$ In general, the longer the side chain, the more efficient the corresponding $\mathrm{PIP}_{2}$ derivative was for PLC-promoted hydrolysis. ${ }^{25}$ These results are supported by the crystal structure 26,27 of the catalytic domain of PLC- $\delta 1$ in complex with $\mathrm{IP}_{3}$; the 1-, 4-, and 
5-phosphates and the 2- and 3-hydroxyls of $\mathrm{IP}_{3}$ interact with PLC- $\delta 1$, and mutation of these interacting residues greatly reduced the capacity of PLC- $\delta 1$ to hydrolyze $\mathrm{PIP}_{2}{ }^{28}$

Consequently, modifications of $\mathrm{PIP}_{2}$ to develop new PLC substrates have avoided targeting the inositol headgroup and have instead focused on the diacylglycerol side chain. For example, we $\mathrm{e}^{29}$ and others ${ }^{30-33}$ have developed fluorogenic PLC reporters with modifications at the 1-phosphate to monitor PLC activity in vitro. However, these systems are unlikely to be optimal for studies in live cells since potential spatial information on PLC activity will be lost upon cleavage of the fluorophore from the $\mathrm{PIP}_{2}$ derivative.

To our knowledge, selective modification of the 6-OH has not been explored despite extensive previous efforts synthesizing $\mathrm{PIP}_{2}$ analogues for novel functions and assays. The structure of PLC- $\delta 1$ bound to $\mathrm{IP}_{3}$ highlights a lack of direct interaction between the lipase active site and the 6-OH group, indicating that the 6-OH is solvent exposed and its modification in PIP $_{2}$ is likely tolerated within the active site of PLCs. Consequently, we designed and synthesized three PIP $_{2}$ derivatives (Figure 1) and investigated their capacity to be hydrolyzed by PLC- $\delta 1$. Probe 1 has a free 6-OH identical to endogenous $\mathrm{PIP}_{2}$ while probes $\mathbf{2}$ and $\mathbf{3}$ have modified 6-OH groups, with a propyl modification in $\mathbf{2}$ and an extended hydroxy in 3 . The incorporation of a fluorescent group at the $s n-1$ position of the DAG side chain provides a sensitive detection of both the substrate and the product by fluorescence, thus avoiding the use of radioactive materials and providing a potential avenue for the use of realtime monitoring of phospholipase activity in cells with high spatiotemporal resolution and high throughput.

\section{EXPERIMENTAL PROCEDURES}

\section{Kinetic Studies of Probes 1-3}

Enzymatic Reactions-The fluorescent PIP $_{2}$ derivatives were dissolved in water to make working solutions at $432,324,216,108,54,32,24$, or $12 \mu \mathrm{M}$. To these solutions $(20 \mu \mathrm{L})$ were added a $6 \mathrm{X}$ buffer $(5 \mu \mathrm{L})$ that contains HEPES ( $300 \mathrm{mM}, \mathrm{pH} 7.2), \mathrm{KCl}(420 \mathrm{mM})$, $\mathrm{CaCl}_{2}(17.8 \mathrm{mM})$, EGTA $(18 \mathrm{mM})$, DTT $(12 \mathrm{mM})$, and $3 \%$ cholate. The reaction was initiated by adding a solution $(5 \mu \mathrm{L})$ that contains purified, full-length PLC- $\delta 1(0.05$ or 0.1 $\mathrm{ng} / \mu \mathrm{L}$, final concentration) and BSA $(1 \mathrm{mg} / \mathrm{mL})$, and the reaction mixtures were incubated at $25{ }^{\circ} \mathrm{C}$. At indicated time points, samples were taken out of the reaction mixtures with a multichannel pipet $(1 \mu \mathrm{L})$ and spotted on TLC plates (Merck, Silica Gel-60). The TLC plates were then developed with $\mathrm{CHCl}_{3}: \mathrm{MeOH}: \mathrm{H}_{2} \mathrm{O}(100: 20: 1)$ and scanned with a Typhoon 9400 Variable Mode Imager $\left(\lambda_{\mathrm{ex}} / \lambda_{\mathrm{em}}=488 \mathrm{~nm} / 520 \mathrm{~nm}\right)$. The fluorescence of DAG and PIP 2 derivatives on the TLC plate was quantified with ImageQuant software (V.5.0).

Fluorescence Calibration and Reaction Rate Calculation-To a set of water solutions $(20 \mu \mathrm{L})$ containing various concentrations $(432,324,216,108,54,32,24$, and 12 $\mu \mathrm{M})$ of $\mathrm{PIP}_{2}$ derivative 1 was added the $6 \mathrm{X}$ buffer solution $(5 \mu \mathrm{L})$ as defined previously and a PLC solution $(5 \mu \mathrm{L})$ containing purified, full-length PLC- $\delta 1(10 \mathrm{ng} / \mu \mathrm{L}$, final concentration) and BSA $(1 \mathrm{mg} / \mathrm{mL})$. The reaction mixtures were incubated at $25{ }^{\circ} \mathrm{C}$ for $2 \mathrm{~h}$ to completely convert probe $\mathbf{1}$ to DAG. As a control, the reactions were also carried out in the presence of BSA (PLC free). These two sets of reaction mixtures were spotted on TLC plates which were subsequently developed and the fluorescence was quantified. The fluorescence was plotted against concentration for probe 1 or DAG. The slope of the plot for probe 1 was 0.66 -fold of that for DAG. Consequently, the amount of DAG that was generated from the reaction was calculated with the formula

$\operatorname{DAG}(\mathrm{pmol})=$ initialPIP 2 concentration $(\mu \mathrm{M}) \times \operatorname{volume}(\mu \mathrm{L}) \times(0.66 \times a) /(0.66 \times a+b)$ 
where $a=$ fluorescence of DAG and $b=$ fluorescence of $\mathrm{PIP}_{2}$.

\section{Kinetic Studies of Endogenous $\mathrm{PIP}_{\mathbf{2}}$}

A mixture of $\mathrm{PIP}_{2}$ (Avanti Polar Lipids) and $30000 \mathrm{cpm}$ of $\left[{ }^{3} \mathrm{H}\right] \mathrm{PIP}_{2}$ (Perkin-Elmer) was dried under a stream of nitrogen and resuspended in assay buffer that contains HEPES (50 $\mathrm{mM}, \mathrm{pH} 7.2), \mathrm{KCl}(70 \mathrm{mM})$, EGTA $(3 \mathrm{mM})$, DTT $(2 \mathrm{mM}), \mathrm{CaCl}_{2}(2.96 \mathrm{mM}), 0.5 \%$ cholate, and BSA $(0.2 \mathrm{mg} / \mathrm{mL})$. The resulting lipid stock was diluted to obtain final assay conditions with either $216,144,72,36,24,16,8$, or $4 \mu \mathrm{M} \mathrm{PIP}{ }_{2}$ in assay buffer ( $50 \mu \mathrm{L}$, final volume). Assays were initiated by the addition of purified, full-length PLC- $\delta 1(0.075 \mathrm{ng})$ in assay buffer $(10 \mu \mathrm{L})$. After incubation at $25^{\circ} \mathrm{C}$ for $10 \mathrm{~min}$, reactions were stopped by the addition of $10 \%(\mathrm{v} / \mathrm{v})$ trichloroacetic acid $(200 \mu \mathrm{L})$ and $10 \mathrm{mg} / \mathrm{mL} \mathrm{BSA}(100 \mu \mathrm{L})$ to precipitate proteins and uncleaved lipids. Centrifugation of the reaction mixture isolated soluble $\left[{ }^{3} \mathrm{H}\right]$ $\mathrm{IP}_{3}$, which was quantified using liquid scintillation counting.

\section{RESULTS AND DISCUSSION}

\section{Synthesis of the Fluorescent Probes}

Fluorescent $\mathrm{PIP}_{2}$ derivatives with free 6-OH such as 1 have been used to image cellular $\mathrm{PIP}_{2}$ localization ${ }^{34}$ and as probes for metabolic enzymes such as phosphoinositide 3-kinase (PI3K) ${ }^{35}$ Consequently, the synthesis of $\mathbf{1}$ follows the literature procedure. ${ }^{36-38}$ In contrast, $\mathrm{PIP}_{2}$ analogues with 6-OH selectively modified have not been reported and their syntheses are challenging. To synthesize the probe $\mathbf{2}$ (Scheme 1) with 6-OH group protected as its propyl ether, we started with the known inositol derivative $\mathbf{4}$. Alkylation of $\mathbf{4}$ with allyl bromide followed by deacetalization with trifluoroacetic acid (TFA) generated $\mathbf{5}$ in $74 \%$ yield. The diol in $\mathbf{5}$ was subsequently protected as the corresponding methoxymethyl (MOM) ethers. Next, the corresponding methoxymethyl (MOM) ethers. Next, the tetraisopropyldisiloxane (TIPDS) group was removed by treating with hydrofluoride (HF) in $\mathrm{CHCl}_{3} / \mathrm{CH}_{3} \mathrm{CN}$. The resulting hydroxy groups were phosphorylated to form 7 in a two-step sequence: first reacted with dibenzyl diisopropylphosphoramidite in the presence of tetrazole and then oxidized by 3 -chloroperoxybenzoic acid (mCPBA). The tertbutyldiphenylsilyl (TBDPS) protection was removed by tetrabutylammonium fluoride (TBAF) to form alcohol $\mathbf{8}$, which was coupled to the diacylglycerol side chain $\mathbf{9}$ to form $\mathbf{1 0}$ in $90 \%$ yield through phosphorylation followed by oxidation with tert-butyl peroxide ( $t$ $\mathrm{BuOOH}$ ). To remove the MOM protective groups, compound $\mathbf{1 0}$ was treated with trimethylsilyl bromide (TMSBr) in $\mathrm{CH}_{2} \mathrm{Cl}_{2}$ followed by methanolysis. The benzyl protective groups were also partially removed during this process. Hydrogenolysis completed the deprotection of both benzyl and carbobenzyloxy $(\mathrm{Cbz})$ groups and reduced the allyl to propyl group to form 11. Finally, the terminal amine was acylated with activated fluorescein 12 to generate the fluorescent $\mathrm{PIP}_{2}$ derivative 2 with 6-OH capped as a propyl ether. The overall yield of the synthesis was $37 \%$.

To synthesize the probe $\mathbf{3}$ (Scheme 2), olefin metathesis of $\mathbf{6}$ with MOM-protected allylic alcohol was carried out. We did not attempt to quantify the $E / Z$ ratio although the formed double bond had predominantly the $E$ configuration as judged by NMR. Instead, the olefin was directly subjected to hydrogenation to form $\mathbf{1 3}$. In a sequence that is analogous to the synthesis of probe $\mathbf{2}$, the diol $\mathbf{1 3}$ was used to generate probe $\mathbf{3}$. The overall yield of this sequence was $15 \%$.

\section{Thin-Layer Chromatography Coupled with Fluorescence Scanning as a New Assay for PLC Activity}

The classical in-vitro assay of PLC activity requires the use of radioactive $\mathrm{PIP}_{2}$, particularly tritium-labeled $\mathrm{PIP}_{2}$, as the PLC substrate. To avoid the use of radioactive $\mathrm{PIP}_{2},{ }^{31} \mathrm{P}$ NMR 
has been used to monitor PLC-catalyzed reactions. ${ }^{39}$ However, the concentration of $\mathrm{PIP}_{2}$ has to be high $(>0.5 \mathrm{mM})$ to obtain accurate measurement, and these techniques are not amenable to large numbers of samples. Existing fluorogenic ${ }^{31,32}$ and luminescence-based ${ }^{33}$ reporters have the advantage of continuous monitoring of PLC activity with high sensitivity. However, these reporters typically replace the diacylglycerol unit connected to the 1phosphate in $\mathrm{PIP}_{2}$, thereby limiting their utility to faithfully recapitulate intracellular events. In contrast, 6-OH analogues provide unexplored potential to produce useful biosensors of PLC activity in cells.

The fluorescent PIP $_{2}$ derivative 1 has key structural features of endogenous $\mathrm{PIP}_{2}$ including an identical inositol phosphate headgroup and a diacylglycerol side chain. Derivative $\mathbf{1}$ and its expected PLC-dependent hydrolysis products (Figure 2A) are predicted to be readily separable by either TLC or column chromatography, and subsequent detection by fluorescence should provide a new assay for PLC activity. To validate this format, purified PLC- $\delta 1$ was used to hydrolyze probe 1 . Based on sequence and structural similarities, the catalytic domain of PLC- $\delta 1$ is representative of the entire family of PLC isozymes. The enzymology of PLC- $\delta 1$ has also been extensively studied $2026,28,40-42$, benefits from the unique structure of PLC- $\delta 1$ bound to $\mathrm{IP}_{3}$ within its active site. The purified enzyme was incubated with probe $\mathbf{1}$ at room temperature for $\mathbf{1 0} \mathrm{min}$, and the mixture was separated on TLC and detected by fluorescence. Fluorescence at the origin of application represents probe 1 and a second fluorescent component appeared as a function of increasing amounts of time during the initial incubation (Figure 2B). This new component was confirmed by LC-MS analysis to be the diacylglycerol derivatives predicted to be generated upon hydrolysis of probe 1 by PLC- $\delta 1$. When probe 1 was incubated with catalytically inactive PLC- $\delta 1$ (E341A), ${ }^{28}$ no new fluorescent components were formed (Figure 2B), indicating that the hydrolysis of $\mathbf{1}$ is dependent on the lipase activity of PLC- $\delta 1$.

Conditions were established to quantify the fluorescent DAG derivative formed during the reaction. Briefly, the linear plots of the fluorescence versus concentration for both $\mathbf{1}$ and the corresponding DAG product are shown in Figure 2C. The ratio of the slopes was used as the coefficient to normalize fluorescence readings for quantifications. Accordingly, $8 \%$ of probe 1 was converted to product in Figure 2B. Under identical conditions, 3\% and 5\% of probes 2 and $\mathbf{3}$ were converted to product, respectively. Like probe $\mathbf{1}$, probes $\mathbf{2}$ and $\mathbf{3}$ were not cleaved by catalytically inactive PLC- $\delta 1$ (E341A) suggesting that both are selective substrates for PLC- $\delta 1$.

\section{Kinetic Studies of Probes 1-3 with PLC- $\delta 1$}

As highlighted in Figure 2B, probes 1-3 were cleaved by PLC- $\delta 1$ with different efficiencies. To further define these probes as PLC substrates for future development of PLC sensors, we carried out detailed kinetic studies to measure $K_{\mathrm{M}}$ and $V_{\max }$ of these probes in PLCcatalyzed reactions. For comparison, enzyme kinetics using $\mathrm{PIP}_{2}$ as the substrate were quantified as previously described ${ }^{43}$ by varying the bulk concentration of $\left[{ }^{3} \mathrm{H}\right] \mathrm{PIP}_{2}-$ containing vesicles.

To increase the efficiency and accuracy of the kinetic measurements, we carried out the experiments with probes 1-3 in a 96-well plate (Figure S1). At the indicated time, the samples were taken from reaction mixtures with a multichannel pipet and loaded directly onto the TLC plates. The fluorescent components in the reaction mixture were then separated and quantified by fluorescence. All the measurements were under initial rate conditions (Figures $\mathrm{S} 2$ ). $K_{\mathrm{M}}$ and $V_{\max }$ were then calculated by fitting the data to the Michaelis-Menten equation (Figure 3A,c,). The $K_{\mathrm{M}}$ for probe 1 was $39 \pm 4.0 \mu \mathrm{M}$ with a $V_{\max }$ of $94 \pm 0.9 \mathrm{pmol} /(\mathrm{ng} \min )$ while the $K_{\mathrm{M}}$ for probe 2 was $67 \pm 9.6 \mu \mathrm{M}$ with a $V_{\max }$ of 
$32 \pm 1.8 \mathrm{pmol} /(\mathrm{ng} \min )$. Capping of the 6-OH with a propyl group decreased $V_{\max }$ and increased $K_{\mathrm{M}}$, suggesting that the modification at 6-OH might interfere with the key interactions of other substitutions in the inositol headgroup with PLC- $\delta 1$. In addition, the propyl group may increase the steric hindrance around the 1-phosphate, making the PLCcatalyzed nucleophilic addition of the 2-OH to the 1-phosphate a slower process. Interestingly, relative to probe $\mathbf{2}$, probe 3 further increased $K_{\mathrm{M}}(128 \pm 15.3 \mu \mathrm{M})$ while having a less detrimental effect on $V_{\max }(67 \pm 9.6 \mathrm{pmol} /(\mathrm{ng} \min ))$, suggesting that increasing the length of the substitution at the $6-\mathrm{OH}$ disrupts interactions with PLC- $\delta 1$ while the terminal hydroxy of the substitution may participate in substrate-assisted catalysis to facilitate phospholipase activity. In both cases, the $K_{\mathrm{M}}$ and $V_{\max }$ of $\mathbf{2}$ and $\mathbf{3}$ are within a 3fold range of equivalent values for probe 1, which are similar to those for the endogenous $\mathrm{PIP}_{2}$ (Figure 3B,C). Consequently, modifying the 6-OH generate functional $\mathrm{PIP}_{2}$ derivatives that potentially can be applied to monitor PLC activity spatiotemporally.

\section{CONCLUSION}

In conclusion, we have developed an efficient synthesis to prepare $\mathrm{PIP}_{2}$ derivatives modified at the 6-hydroxy group, making it possible to explore the role of the 6-OH in $\mathrm{PIP}_{2}$ for PLCcatalyzed hydrolysis. Several of these derivatives have been characterized in a new TLCbased assay that features straightforward separation of products from the reaction mixture and sensitive detection for their capacity as substrates of PLC- $\delta 1$. These modifications at the 6-OH group result in derivatives that are excellent PLC substrates with marginally lower $V_{\max }$ and higher $K_{\mathrm{M}}$ values compared to the unmodified parent $\mathrm{PIP}_{2}$ derivative and endogenous $\mathrm{PIP}_{2}$. These results demonstrate that the 6-OH group can be modified for new functions, setting the stage for further development of sensors selective for PLC isozymes and useful for monitoring the spatiotemporal dynamics of these enzymes in living cells.

\section{Supplementary Material}

Refer to Web version on PubMed Central for supplementary material.

\section{Acknowledgments}

We thank Dr. Stephanie Hicks for providing purified PLC- $\delta 1$ and Dr. Weigang Huang for helpful discussions.

Funding

This work was funded by National Institutes of Health (GM098894 and GM057391).

\section{ABBREVIATIONS}

$\begin{array}{ll}\text { PLC } & \text { phospholipase C } \\ \text { PIP }_{2} & \text { phosphatidylinositol 4,5-bi-sphosphate } \\ \text { IP }_{3} & \text { inositol 1,4,5-trisphosphate } \\ \text { DAG } & \text { diacylgly-cerol }\end{array}$

\section{REFERENCES}

1. Gresset A, Sondek J, Harden TK. The phospholipase C isozymes and their regulation. Subcell. Biochem. 2012; 58:61-94. [PubMed: 22403074]

2. Harden TK, Waldo GL, Hicks SN, Sondek J. Mechanism of activation and inactivation of Gq/ phospholipase C-beta signaling nodes. Chem. Rev. 2011; 111:6120-6129. [PubMed: 21988240] 
3. Nakamura Y, Fukami K. Roles of phospholipase C isozymes in organogenesis and embryonic development. Physiology Bethesda. 2009; 24:332-341. [PubMed: 19996364]

4. Cocco L, Faenza I, Follo MY, Billi AM, Ramazzotti G, Papa V, Martelli AM, Manzoli L. Nuclear inositides: PI-PLC signaling in cell growth, differentiation and pathology. Adv. Enzyme Regul. 2009; 49:2-10. [PubMed: 19159640]

5. Liao HJ, Kume T, McKay C, Xu MJ, Ihle JN, Carpenter G. Absence of erythrogenesis and vasculogenesis in Plcg1-deficient mice. J. Biol. Chem. 2002; 277:933S-9341.

6. Saunders CM, Swann K, Lai FA. PLCzeta, a sperm-specific PLC and its potential role in fertilization. Biochem. Soc. Symp. 2007:23-36. [PubMed: 17233577]

7. Sala G, Dituri F, Raimondi C, Previdi S, Maffucci T, Mazzoletti M, Rossi C, Iezzi M, Lattanzio R, Piantelli M, Iacobelli S, Broggini M, Falasca M. Phospholipase Cgamma1 is required for metastasis development and progression. Cancer Res. 2008; 68:10187-10196. [PubMed: 19074886]

8. Parsons DW, Jones S, Zhang X, Lin JC, Leary JR, Angenendt P, Mankoo P, Carter H, Siu IM, Gallia GL, Olivi A, McLendon R, Rasheed BA, Keir S, Nikolskaya T, Nikolsky Y, Busam DA, Tekleab H, Diaz LA Jr, Hartigan J, Smith DR, Strausberg RL, Marie SK, Shinjo SM, Yan H, Riggins GJ, Bigner DD, Karchin R, Papadopoulos N, Parmigiani G, Vogelstein B, Velculescu VE, Kinzler KW. An integrated genomic analysis of human glioblastoma multiforme. Science. 2008; 321:1807-1812. [PubMed: 18772396]

9. Ikuta S, Edamatsu H, Li M, Hu L, Kataoka T. Crucial role of phospholipase C epsilon in skin inflammation induced by tumor-promoting phorbol ester. Cancer Res. 2008; 68:64-72. [PubMed: 18172297]

10. Shepard CR, Kassis J, Whaley DL, Kim HG, Wells A. PLC gamma contributes to metastasis of in situ-occurring mammary and prostate tumors. Oncogene. 2007; 26:3020-3026. [PubMed: 17130835]

11. Bertagnolo V, Benedusi M, Brugnoli F, Lanuti P, Marchisio M, Querzoli P, Capitani S. Phospholipase C-beta 2 promotes mitosis and migration of human breast cancer-derived cells. Carcinogenesis. 2007; 28:1638-1645. [PubMed: 17429106]

12. Cocco L, Manzoli L, Palka G, Martelli AM. Nuclear phospholipase C beta1, regulation of the cell cycle and progression of acute myeloid leukemia. Adv. Enzyme Regul. 2005; 45:126-135. [PubMed: 16024064]

13. Bai Y, Edamatsu H, Maeda S, Saito H, Suzuki N, Satoh T, Kataoka T. Crucial role of phospholipase Cepsilon in chemical carcinogen-induced skin tumor development. Cancer Res. 2004; 64:8808-8810. [PubMed: 15604236]

14. Hinkes B, Wiggins RC, Gbadegesin R, Vlangos CN, Seelow D, Nurnberg G, Garg P, Verma R, Chaib H, Hoskins BE, Ashraf S, Becker C, Hennies HC, Goyal M, Wharram BL, Schachter AD, Mudumana S, Drummond I, Kerjaschki D, Waldherr R, Dietrich A, Ozaltin F, Bakkaloglu A, Cleper R, Basel-Vanagaite L, Pohl M, Griebel M, Tsygin AN, Soylu A, Muller D, Sorli CS, Bunney TD, Katan M, Liu J, Attanasio M, O'Toole JF, Hasselbacher K, Mucha B, Otto EA, Airik R, Kispert A, Kelley GG, Smrcka AV, Gudermann T, Holzman LB, Nurnberg P, Hildebrandt F. Positional cloning uncovers mutations in PLCE1 responsible for a nephrotic syndrome variant that may be reversible. Nat. Genet. 2006; 38:1397-1405. [PubMed: 17086182]

15. Shi TJ, Liu SX, Hammarberg H, Watanabe M, Xu ZQ, Hokfelt T. Phospholipase C $\{$ beta $\} 3$ in mouse and human dorsal root ganglia and spinal cord is a possible target for treatment of neuropathic pain. Proc. Natl. Acad. SciUSA. 2008; 105:20004-20008.

16. Harden TK, Hicks SN, Sondek J. Phospholipase C isozymes as effectors of Ras superfamily GTPases. J. Lipid Res. 2009; 50(Suppl):S243-S248. [PubMed: 19033212]

17. Seifert JP, Zhou Y, Hicks SN, Sondek J, Harden TK. Dual activation of phospholipase C-epsilon by Rho and Ras GTPases. J. Biol. Chem. 2008; 283:29690-29698. [PubMed: 18765661]

18. Harden TK, Sondek J. Regulation of phospholipase C isozymes by ras superfamily GTPases. Annu. Rev. Pharmacol. Toxicol. 2006; 46:355-379. [PubMed: 16402909]

19. Wu Y, Perisic O, Williams RL, Katan M, Roberts MF. Phosphoinositide-specific phospholipase C delta1 activity toward micellar substrates, inositol 1,2-cyclic phosphate, and other water-soluble substrates: a sequential mechanism and allosteric activation. Biochemistry. 1997; 36:1122311233. [PubMed: 9287165] 
20. Essen LO, Perisic O, Katan M, Wu Y, Roberts MF, Williams RL. Structural mapping of the catalytic mechanism for a mammalian phosphoinositide-specific phospholipase C. Bio chemistry. 1997; 36:1704-1718.

21. Bruzik KS, Tsai MD. Toward the mechanism of phosphoinositide-specific phospholipases C. Bioorg. Med. Chem. 1994; 2:49-72. [PubMed: 7922124]

22. Serunian LA, Haber MT, Fukui T, Kim JW, Rhee SG, Lowenstein JM, Cantley LC. Polyphosphoinositides produced by phosphatidylinositol 3-kinase are poor substrates for phospholipases C from rat liver and bovine brain. J. Biol. Chem. 1989; 264:17809-17815.

23. Bruzik KS, Hakeem AA, Tsai MD. Are D- and L-chiro-phosphoinositides substrates of phosphatidylinositol-specific phospholipase C? Biochemistry. 1994; 33:8367-8374. [PubMed: 8031771]

24. Rebecchi MJ, Eberhardt R, Delaney T, Ali S, Bittman R. Hydrolysis of short acyl chain inositol lipids by phospholipase C-delta 1. J. Biol. Chem. 1993; 268:1735-1741. [PubMed: 8380575]

25. Liu Y, Mihai C, Kubiak RJ, Rebecchi M, Bruzik KS. Phosphorothiolate analogues of phosphatidylinositols as assay substrates for phospholipase C. ChemBioChem. 2007; 8:14301439. [PubMed: 17659518]

26. Essen LO, Perisic O, Cheung R, Katan M, Williams RL. Crystal structure of a mammalian phosphoinositide-specific phospholipase C delta. Nature. 1996; 380:595-602. [PubMed: 8602259]

27. Williams RL, Katan M. Structural views of phosphoinositide-specific phospholipase C: signalling the way ahead. Structure. 1996; 4:1387-1394. [PubMed: 8994965]

28. Ellis MV, James SR, Perisic O, Downes CP, Williams RL, Katan M. Catalytic domain of phosphoinositide- specific phospholipase C (PLC). Mutational analysis of residues within the active site and hydrophobic ridge of plcdelta1. J Biol. Chem. 1998; 273:11650-11659. [PubMed: 9565585]

29. Huang W, Hicks SN, Sondek J, Zhang Q. A fluorogenic, small molecule reporter for mammalian phospholipase C isozymes. ACS Chem. Biol. 2011; 6:223-228. [PubMed: 21158426]

30. Rose TM, Prestwich GD. Synthesis and evaluation of fluorogenic substrates for phospholipase D and phospholipase C. Org. Lett. 2006; 8:2575-2578. [PubMed: 16737317]

31. Zaikova TO, Rukavishnikov AV, Birrell GB, Griffith OH, Keana JF. Synthesis of fluorogenic substrates for continuous assay of phosphatidylinositol-specific phospholipase C. Bioconjugate Chem. 2001; 12:307-313.

32. Rukavishnikov AV, Zaikova TO, Birrell GB, Keana JF, Griffith OH. Synthesis of a new fluorogenic substrate for the continuous assay of mammalian phosphoinositide-specific phospholipase C. Bioorg. Med. Chem. Lett. 1999; 9:1133-1136. [PubMed: 10328299]

33. Ryan M, Huang JC, Griffith OH, Keana JF, Volwerk JJ. A chemiluminescent substrate for the detection of phosphatidylinositol-specific phospholipase C. Anal. Biochem. 1993; 214:548-556. [PubMed: 8109748]

34. Ozaki S, DeWald DB, Shope JC, Chen J, Prestwich GD. Intracellular delivery of phosphoinositides and inositol phosphates using polyamine carriers. Proc. Natl. Acad. Sci. USA. 2000; 97:1128611291. [PubMed: 11005844]

35. Huang W, Jiang D, Wang X, Wang K, Sims CE, Allbritton NL, Zhang Q. Kinetic analysis of PI3K reactions with fluorescent PIP2 derivatives. Anal. Bioanal. Chem. 2011; 401:1881-1888. [PubMed: 21789487]

36. Chen J, Profit AA, Prestwich GD. Synthesis of Photoactivatable 1,2-O-Diacyl-sn-glycerol Derivatives of 1-L-Phospha- tidyl-D-myo-inositol 4,5-Bisphosphate (PtdInsP(2)). and 3,4,5-Trisphosphate (PtdInsP(3)). J. Org. Chem. 1996; 61:630S-6312.

37. Kubiak RJ, Bruzik KS. Comprehensive and uniform synthesis of all naturally occurring phosphorylated phospha-tidylinositols. J. Org. Chem. 2003; 68:960-968.

38. Bruzik KS, Tsai MD. Efficient and Systematic Syntheses of Enantiomerically Pure and Regiospecifically Protected Myoinositols. J. Am. Chem. Soc. 1992; 114:6361-6374.

39. Roberts MF, Redfield AG. High-resolution 31p field cycling NMR as a probe of phospholipid dynamics. J. Am. Chem. Soc. 2004; 126:13765-13777. 
40. Cheng HF, Jiang MJ, Chen CL, Liu SM, Wong LP, Lomasney JW, King K. Cloning and identification of amino acid residues of human phospholipase $\mathrm{C}$ delta 1 essential for catalysis. J. Biol. Chem. 1995; 270:5495-5505.

41. Lomasney JW, Cheng HF, Wang LP, Kuan Y, Liu S, Fesik SW, King K. Phosphatidylinositol 4,5bisphosphate binding to the pleckstrin homology domain of phospholipase C-delta1 enhances enzyme activity. J. Biol. Chem. 1996; 271:25316-25326.

42. Yagisawa H, Sakuma K, Paterson HF, Cheung R, Allen V, Hirata H, Watanabe Y, Hirata M, Williams RL, Katan M. Replacements of single basic amino acids in the pleckstrin homology domain of phospholipase C-delta1 alter the ligand binding, phospholipase activity, and interaction with the plasma membrane. J. Biol. Chem. 1998; 273:417-424.

43. Zhou Y, Sondek J, Harden TK. Activation of human phospholipase C-eta2 by Gbetagamma. Biochemistry. 2008; 47:4410-4417. [PubMed: 18361507] 


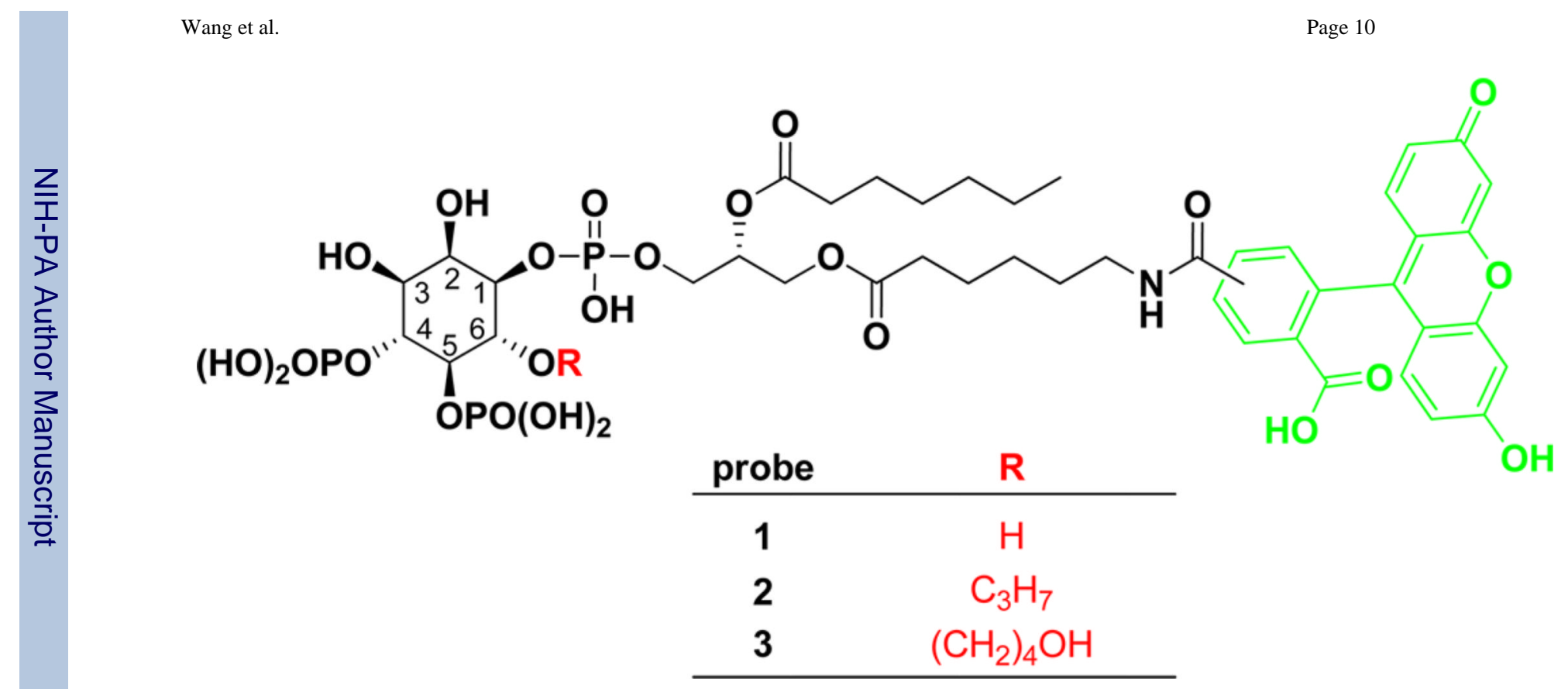

Figure 1.

Chemical structures of the PIP $_{2}$ derivatives 1-3 as PLC substrates. 
A
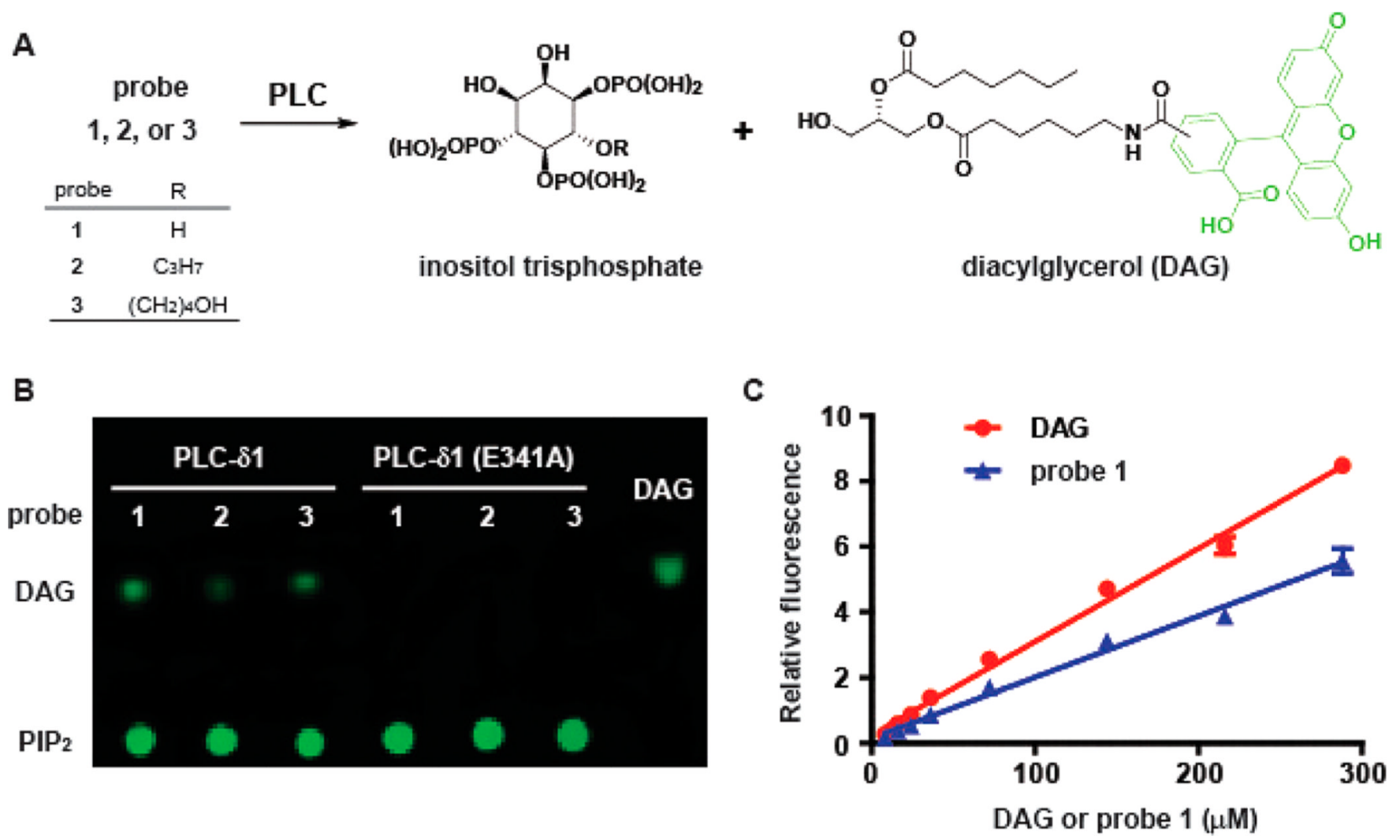

Figure 2.

Validation of the TLC-fluorescence assay. (A) Probes 1-3 are cleaved by PLC- $\delta 1$ to form inositol trisphosphate and diacylglycerol (DAG) derivatives. (B) The separation of PIP $_{2}$ derivatives 1-3 and their corresponding DAGs on thin-layer chromatography (TLC). The reaction mixture $(1 \mu \mathrm{L})$ was spotted on the TLC plate and separated by $\mathrm{CHCl}_{3}: \mathrm{MeOH}: \mathrm{H}_{2} \mathrm{O}$ (100:20:1). The fluorescent compounds were detected by a Typhoon 9400 variable mode imager $\left(\lambda_{\mathrm{ex}} / \lambda_{\mathrm{em}}=488 \mathrm{~nm} / 520 \mathrm{~nm}\right.$ ). (C) Plot of fluorescence versus concentration of DAG or probe 1 . 

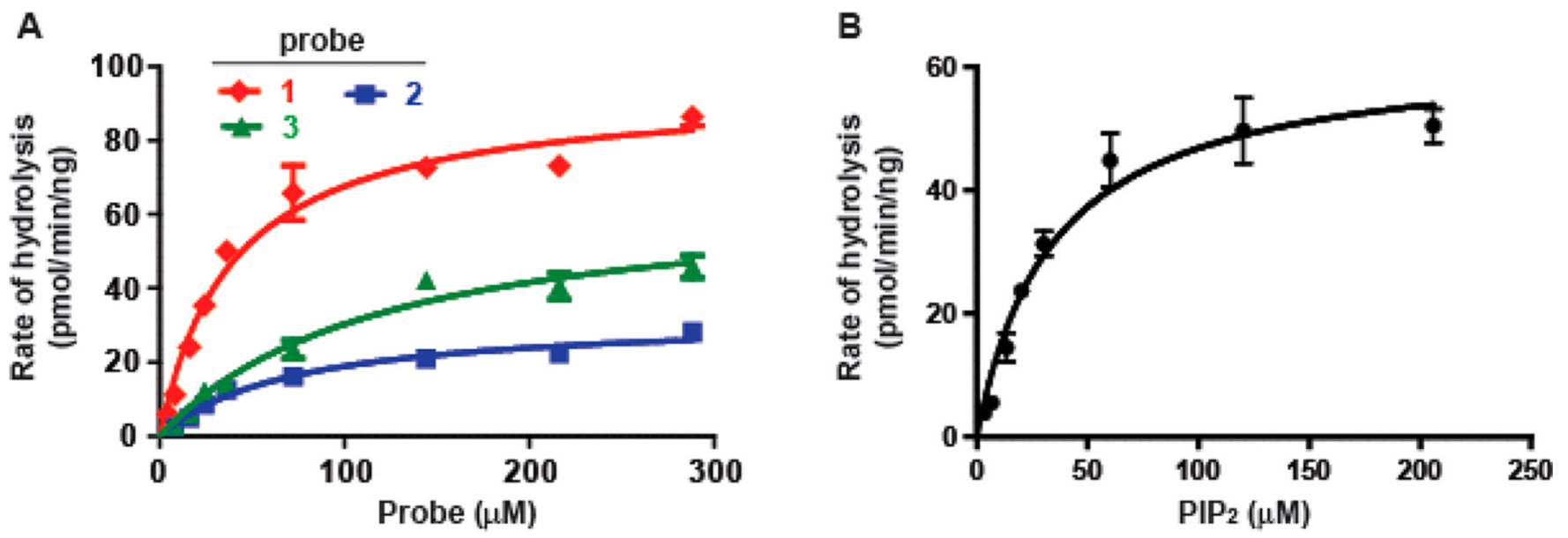

C

\begin{tabular}{ccccc} 
& Probe 1 & Probe 2 & Probe 3 & PIP $_{2}$ \\
\hline$K_{\mathrm{M}}(\mu \mathrm{M})$ & $39 \pm 4.0$ & $67 \pm 9.6$ & $128 \pm 15.3$ & $40 \pm 4.7$ \\
$V_{\max }(\mathrm{pmol} / \mathrm{ng} / \mathrm{min})$ & $94 \pm 0.9$ & $32 \pm 1.8$ & $67 \pm 9.6$ & $60 \pm 3.8$ \\
\hline
\end{tabular}

Figure 3.

Kinetic studies of probes 1-3 or endogenous PIP 2 with PLC- $\delta 1$. (A) The initial velocities of hydrolysis of $\mathbf{1}, \mathbf{2}$, or $\mathbf{3}$ at various concentrations were fitted to the Michaelis-Menten equation. (B) Hydrolysis rates of $\mathrm{PIP}_{2}$ at various concentrations were fitted to the Michaelis -Menten equation. (C) $K_{\mathrm{M}}$ and $V_{\max }$ of probes 1-3 and endogenous PIP 2 with PLC- $\delta 1$. 


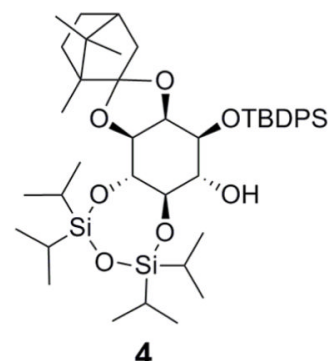

4

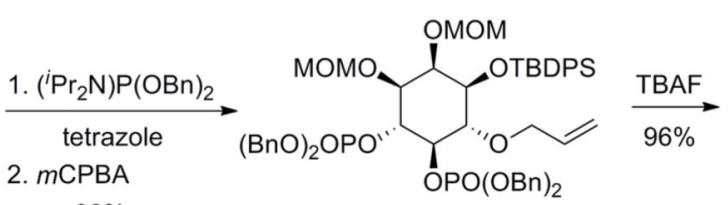

7

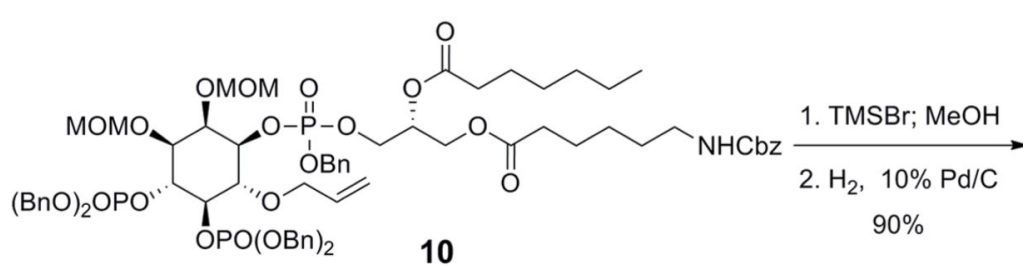

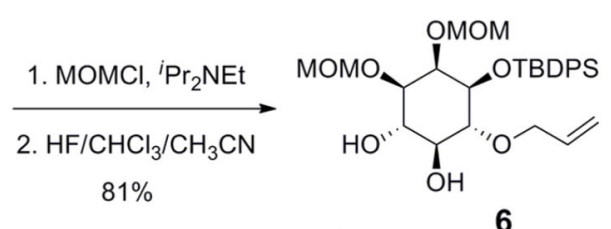

5

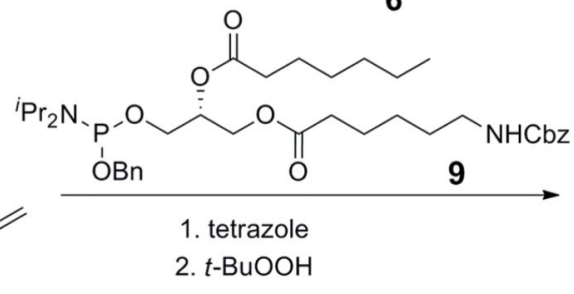

$90 \%$

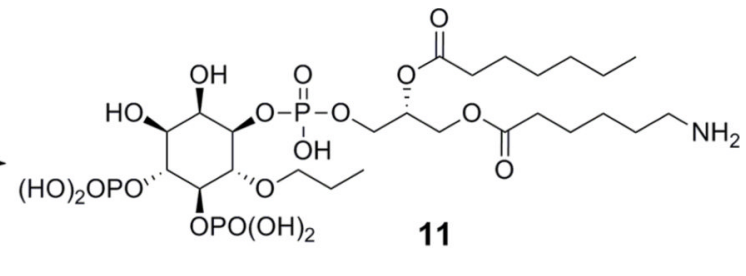

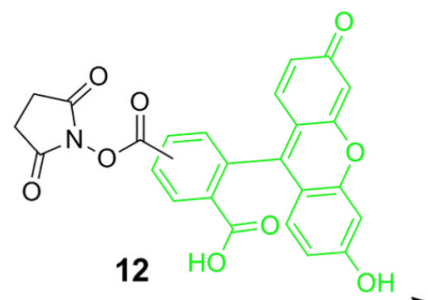

$82 \%$

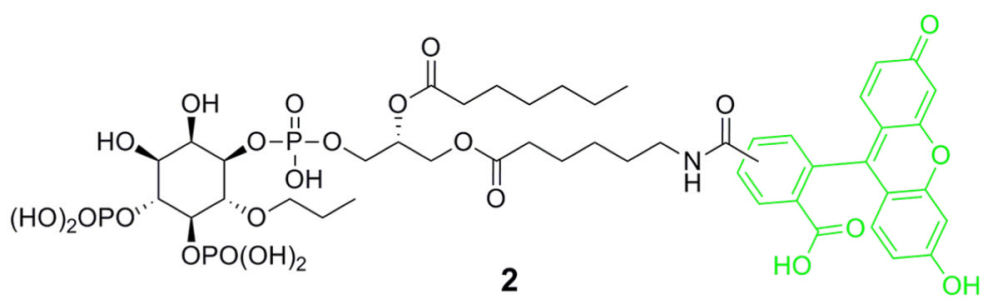

Scheme 1.

Synthesis of Probe 2 

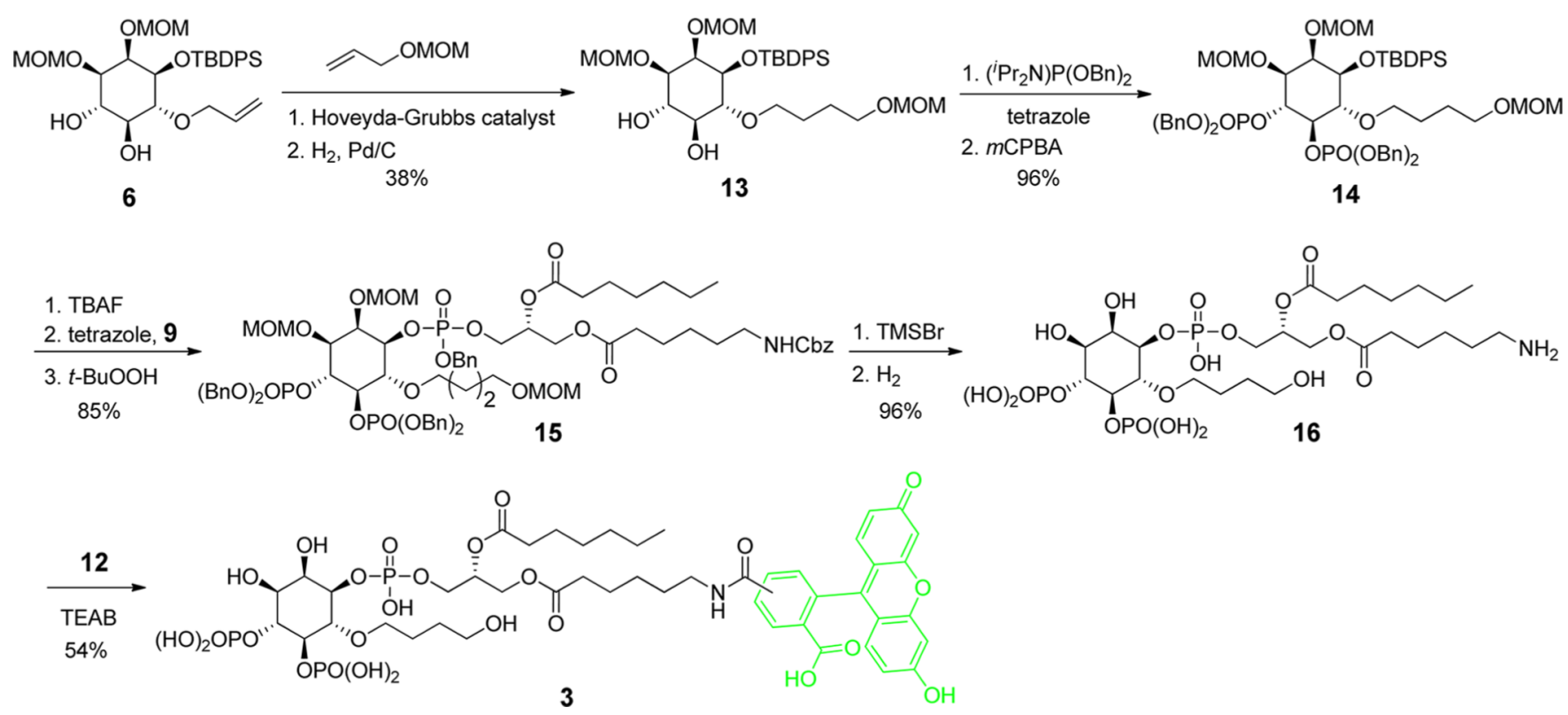

Scheme 2 .

Synthesis of Probe 3 